\title{
Factors Perceived by Caretakers as Barriers to Health Care for Under-Five Children in Mazabuka District, Zambia
}

\author{
H. Halwindi, ${ }^{1}$ S. Siziya, ${ }^{2}$ P. Magnussen, ${ }^{3}$ and A. Olsen $^{3}$ \\ ${ }^{1}$ Department of Community Medicine, School of Medicine, University of Zambia, P.O. Box 50110, Lusaka 10101, Zambia \\ ${ }^{2}$ Department of Clinical Sciences, School of Medicine, Copperbelt University, P.O. Box 71191, Ndola 10101, Zambia \\ ${ }^{3}$ Faculty of Health and Medical Sciences, University of Copenhagen, Thorvaldsensvej 57, 1871 Frederiksberg C, Denmark
}

Correspondence should be addressed to H. Halwindi; hikabasa@yahoo.com

Received 6 February 2013; Accepted 22 February 2013

Academic Editors: F. J. Andrade-Narvaez and P. Horrocks

Copyright (C) $2013 \mathrm{H}$. Halwindi et al. This is an open access article distributed under the Creative Commons Attribution License, which permits unrestricted use, distribution, and reproduction in any medium, provided the original work is properly cited.

\begin{abstract}
In rural areas of Zambia primary health care is provided by rural health centres (RHCs). However, accessibility to these services is limited. In the catchment areas of two RHCs in Mazabuka district (Chivuna and Magoye RHCs) we investigated factors that caretakers perceived as barriers to health care for under five children and how they cope with the barriers. Ten Focus Group Discussions (FGDs) with caretakers of children under-five years of age and key informant interviews with six health workers from the two RHCs, and eight community health workers were conducted in May 2006. The major factors perceived as barriers were poor quality of health services, unavailability of medicines, financial constraints, weak outreach programmes, bad scheduling of health programmes, poor communication, long distance to RHCs and low awareness levels of the importance of taking children for child health week among caretakers. Caretakers' main coping strategy was the use of the folk sector of health care. The findings of this study highlight the challenges that exist in accessing of health care in resource-poor settings and underscore that the provision of health care services of good quality remains a major challenge.
\end{abstract}

\section{Introduction}

Access to health care for children aged below five years (under-five children) is a major public health and development issue. Even the most powerful diagnostic tests, drugs, and vaccines have little public health impact if they do not reach the people that need them the most [1]. Five dimensions of access influence the course of action of the health seeking process: availability, accessibility, affordability, adequacy, and acceptability [2]. Rural populations are especially vulnerable for a number of reasons. Problems of accessibility, including distance, long travel times to the health facilities, scarce public transport, and lack of bicycles, remain key barriers to access in many rural areas. Facilities are less likely to have well trained staff or be stocked with appropriate drugs and equipment than facilities located in urban communities [1]. Low levels of education, and cultural barriers may likewise make health information or other health-related Information,
Education and Communication (IEC) inaccessible [3-5]. Issues related to affordability are major obstacles. Even where health services are available, the cost of seeking care (such as user fees, transport, and opportunity costs) may delay or prevent poor households from accessing the services [6]. In Zambia, for instance, user fees for health care in public facilities were introduced in 1993 under the structural adjustment programme (SAP) but were later abolished in rural areas in 2006 because of the obstacle they created among poor populations in accessing health care. Today, all under-five children and the elderly aged 65 years or older are exempted from paying user fees at rural health centres (RHC), except for a one-off registration fee of ZMK500 ( US \$0.17).

It is estimated that universal coverage with effective interventions could prevent the majority of under-five deaths [7]. However, the current coverage of key survival interventions in Zambia is inadequate to achieve the targeted reduction of under-five mortality by $20 \%$ from the current level of 168 per 
1,000 live births to 134 by 2010 [8]. The Zambia Demographic and Health Survey shows that $68 \%$ of children aged $12-$ 23 months in Zambia were fully vaccinated in 2006 [9]. Although the national coverage for immunization and vitamin A supplementation is high, rural areas perform poorly compared to urban areas [9]. Some rural districts consistently record as low as $15 \%$ coverage of vitamin A supplementation (National Food and Nutrition Commission, 2007 unpublished report). Available data also show that only about $50 \%$ of children with diarrhoea use oral rehydration fluids, antimalarial drugs for fever and antibiotics for pneumonia [3]. Thus, basic social research elucidating factors that hamper people's access to health care can help understand and remedy the barriers affecting poor disadvantaged populations.

A study was designed to investigate the current health facility-based (HF) approach to delivering vitamin A supplementation and anthelminthic drugs to under-five children during child health week (CHW) and compare it with an approach where community-directed treatment (ComDT) approach was added to the HF approach in order to improve treatment coverage. Before implementing the ComDT approach, a study was conducted with the aim of defining the population in the study areas and exploring factors that affect access to health care services in order to ensure that the study would be relevant and acceptable. In this paper we report the problems that caretakers perceived as barriers to accessing health care for their under-five children.

\section{Methods}

2.1. Study Area and Population. This study was conducted in the catchment population of Chivuna and Magoye rural health centres (RHCs) in Mazabuka district in the Southern Province of Zambia. Approximately 70\% of the population in the district is rural, consisting of peasants who depend on subsistence agriculture for food and as a source of income. Maize and cotton are the major crops grown. However, the decline in the price of cotton and the fluctuating price of maize have severely restricted their cultivation for commercial purposes. It is also a common occupation to work in nearby commercial farms on part time or full time basis. The district is mainly inhabited by the Tonga speaking people: the largest tribe in Southern Province. Magoye RHC is about $27 \mathrm{~km}$ from Mazabuka town centre and the district hospital and has an estimated catchment population of under-five children of 2,400. Chivuna RHC lies about $65 \mathrm{~km}$ from Mazabuka town centre and is $40 \mathrm{~km}$ away from the nearest district hospital (Monze general hospital). It has an estimated under-five catchment population of 2,300. The two RHCs are $37 \mathrm{~km}$ apart. In both areas the RHC and community health workers provide general health care. The number of trained community health workers is 8 and 5 for Magoye and Chivuna, respectively. Under-five clinics are held once a week at each RHC and once a month at each outreach post. The outreach posts are locations within the communities where the health centre staff and community health workers conduct specific health programmes like CHW, monthly underfive and antenatal clinics, periodically. In June and December, children aged 12 to 59 months receive anthelminthic drugs and vitamin A supplementation during CHW. There are a number of community-based organizations (CBOs) in the area, but the Neighbourhood Health Committee (NHC) is the main $\mathrm{CBO}$ coordinating all health activities at community level. The functions of the NHC include provision of basic health education to the communities, coordination of all health activities at community level, and acting as a link between the community and the RHC. The health centre supervises the NHCs.

2.2. Recruitment of Participants. The study was carried out in May 2006. Caretakers of under-five children and who lived in the study areas were recruited to participate in focus group discussions (FGD) lasting between 60 and 90 minutes. Recruitment of participants for the FGDs was done through the NHC chairpersons, who identified and selected the eligible women. One of the researchers $(\mathrm{HH})$ together with the NHC chairperson for each neighbourhood (group of villages) met the identified caretakers to invite them to participate in the FGDs, after explaining to them the aim of the study and what was expected from them. The invitation of each caretaker to participate was done a week before the FGD was held, but the participants were reminded of the scheduled FGD by the NHC chairperson a day before the FGD took place. The main inclusion criterion was a caretaker with an under-five child at home. Selected participants in each focus group were not strangers but already acquainted with each other in order to have them discuss more freely. The recruited participants were also balanced in terms of two age groups. That is, equal number of caretakers aged 30 years and below and those aged 31 years and above were recruited. The villages in the catchment area for each RHC were grouped into five local geographical areas based on their proximity to each other. A total of ten FGDs (five in each study area) were conducted. One FGD was held in each local geographical area. The number of FGDs was based on the rule that two FGDs should be conducted for each defining variable, where time and resources allowed [10]. By this method, it was assumed that diverse viewpoints and experiences would be represented. In this case our defining variables were the two age groups and the two study areas, thus eight FGDs. The number of FGDs was increased to ten; five in each study area, in case some FGDs failed to meet the required number of participants. All participants in the FGDs fluently spoke the local language (Tonga). Key informant interviews (KIIs) with three health workers (the clinical officer and two nurses) and four-community health workers from each study area were also conducted using a semi structured questionnaire.

2.3. Data Collection. The FGD guide was pretested and revised twice to produce the final version. The pretesting was conducted in the same study areas but on different participants. The pre-testing was conducted in one randomly selected local geographical area in each study area. The ten FGDs were conducted at the headmen's homes. The NHC chairpersons and headmen recommended this venue. The headman's homestead always had a designated place were community meetings took place. One FGD was conducted 
per day. FGDs were designed to explore general perceptions and attitudes, and to assess consensus or differing opinions about health care access for under-five children. The FGDs were facilitated by a social scientist and notes were taken by the $\mathrm{HH}$. The role taken by the researchers in the data collection was that of an outside observer [10], using their own perspective to enable them to listen, question and interpret the information shared by the participants, at the same time getting the insiders' perspectives from the study participants. A brief profile of each participant was collected at the start of each FGD. This included information on age, marital status, educational attainment, and possession of assets. A series of questions on barriers to health care, developed from a literature review, was thereafter presented by the group facilitator and used to elicit information from the participants of the FGD. Topics introduced for discussion focussed on how caretakers described the health system in terms of meeting the needs of under-five children. In addition, caretakers were specifically asked on the factors responsible for the low attendance during CHW. The coping strategies to the perceived barriers to health care access and the caretakers' suggested solutions for the low attendance during $\mathrm{CHW}$ were also explored. Probes and follow-up questions were used to explore dominant themes and expand discussions. Immediately after each FGD a debriefing was held to evaluate the quality of the session, to check on the responses and to clear up any issues that needed attention before the next FGD.

In addition to the FGDs, KIIs with one clinical officer, two nurses, and four community health workers from each study area were conducted where they were asked to describe the general health seeking behaviour of their communities and clarify on specific matters arising from the FGDs.

2.4. Data Analysis. The data were manually analyzed using a systematic text-analysis procedure [10]. First, a preliminary review of the large amount of text was conducted to reduce and generate specific thematic categories and codes. The codes included key words that represented topics conveyed in the transcripts. More specific descriptive subcodes were assigned to data grouped under these broad categories. For example, during initial coding, data describing difficulties in getting or giving health care were coded as "barriers." During the next level of coding, these data were assigned subcodes such as "cost" or "staffing." Searches were then conducted for each code to bring together text from all FGDs and individual interviews related to each theme. As part of this step, tables were created to list main themes, subthemes, and all quotes related to each subtheme, to determine patterns in the data according to source and summarize perceptions on health service use and delivery.

2.5. Ethical Consideration. The research proposal was reviewed and approved by the University of Zambia Research Ethics Review Committee (Ref.: 003-01-06) and commented on by the Danish National Committee on Biomedical Research Ethics (Ref.: 2006-7041-83) before the research was carried out. In addition, the Ministry of Health $(\mathrm{MoH})$ in Zambia gave permission for the study to be conducted.
During interviews, informed consent was sought from the participants for their participation in the FGDs and KIIs, after an explanation of the objectives of the project. Participants were also told that they were free to withdraw from the study at any time. They were also informed that confidentiality and anonymity would be preserved.

\section{Results}

Table 1 gives a summary of the demographic characteristics of the participants in FGDs. A total of ten FGDs were held, five in Chivuna and five in Magoye. A total of 54 caretakers participated in the five FGDs in Chivuna. The number of participants per FGD was 12, 12, 12, 7, and 11. In Magoye a total of 52 caretakers participated in the FGDs, with 10, 12, 11, 9, and 10 participating in individual FGDs. The FGDs with 7 and 9 participants had low numbers because some participants who had accepted the invitation to participate did not turn up for the FGDs. The distribution of the age of participants, marital status, and education attainment was similar between participants of Chivuna and Magoye. However, the proportion of participants who owned economic assets was higher in Magoye compared to Chivuna. The number of participants whose age was not known in Chivuna and Magoye was five and four, respectively. These were older women who were not sure of their exact year of birth. In addition, seven and three participants in Chivuna and Magoye, respectively, did not disclose their education attainment level.

3.1. Perceived Barriers to Accessing General Health Care Services for Children. The participants were asked to identify barriers to accessing health care services that they encountered. From the discussions, five categories of barriers emerged: poor quality of service at health centres, nonavailability of medicines, financial constraints, inadequate staffing, and the lack of outreach programmes during certain months. An additional set of factors were discussed that specifically involved the CHW. The quotes are identified as FGD-1 for the younger women up to 30 years of age and FGD-2 for the older women above 30 years of age. They are also identified by study area-Chivuna or Magoye.

3.1.1. Poor Quality of Services at the Health Centre. Lack of quality health care was one of the barriers that emerged during the FGDs. The perceptions on the quality of care however were varied in the FGDs. The focus groups generally agreed that the quality of care they received at the health centre was poor. The caretakers' perceived quality of care was mainly focussed on communication, the attitude, and efficiency of health workers, as expressed in the following comments:

“...attention is poor; sometimes they don't give you an explanation of the child's illness" (FGD-1 Chivuna),

“... they don't care because they won't even tell you the medicines they give the child and won't give you time to ask questions" (FGD-1 Magoye), 
TABLE 1: Demographic characteristics of caretakers who participated in the focus group discussions.

\begin{tabular}{|c|c|c|}
\hline & \multicolumn{2}{|c|}{ Frequency of participants } \\
\hline & $\begin{array}{c}n(\%) \text { of } \\
\text { participants in } \\
\text { Chivuna }^{\dagger}\end{array}$ & $\begin{array}{c}n(\%) \text { of } \\
\text { participants in } \\
\text { Magoye }^{*}\end{array}$ \\
\hline \multicolumn{3}{|l|}{ Age } \\
\hline $16-30$ years & $22(40.7)$ & $24(46.2)$ \\
\hline $31-57$ years & $27(50.0)$ & $24(46.2)$ \\
\hline \multicolumn{3}{|l|}{ Marital status } \\
\hline Married & $26(48.1)$ & $23(44.2)$ \\
\hline Single & $18(33.3)$ & $20(38.5)$ \\
\hline Widowed & $10(18.5)$ & $9(17.3)$ \\
\hline \multicolumn{3}{|l|}{ Education attainment ${ }^{* *}$} \\
\hline Grade 1-7 & $22(40.7)$ & $20(38.5)$ \\
\hline Grade 8-9 & $18(33.3)$ & $15(28.8)$ \\
\hline Grade $10-12$ & $4(7.4)$ & $10(19.2)$ \\
\hline$\geq \operatorname{grade} 12$ & $3(5.6)$ & $4(7.7)$ \\
\hline \multicolumn{3}{|l|}{ Economic indicators } \\
\hline Family owns bicycle & $42(77.8)$ & $42(80.8)$ \\
\hline Family owns radio & $33(61.1)$ & $47(90.4)$ \\
\hline Iron/asbestos roof & $16(29.6)$ & $29(55.8)$ \\
\hline Concrete floor & $12(22.2)$ & $23(44.2)$ \\
\hline $\begin{array}{l}\text { Owns domestic } \\
\text { animals }\end{array}$ & $14(25.9)$ & $19(36.5)$ \\
\hline
\end{tabular}

${ }^{\dagger}$ Total number of participants $(N)$ was 54 .

${ }^{\ddagger}$ Total number of participants $(N)$ was 52 .

${ }^{* *}$ Grade is equivalent to the number of years spent in basic education, with, for instance, grade 1 being the first year of primary education.

"They don't give medicines, just Panadol (pain killer) or a prescription when they know we are poor and we cannot afford buying medicines from town" (FGD-2 Chivuna),

"... sometimes they say we also get tired, we need to rest..." (FGD-2, Magoye),

"... most times they don't follow the queue and will first treat the people they know" (FGD-2 Magoye),

"...the personnel at the clinic are selective in treating... even if you have a very ill patient they won't attend to you in good time..." (FGD-1 Magoye),

"They first treat the well to do, those that live in electrified homes" (FGD-2 Magoye).

However, a few voices in the FGDs perceived the attention they received from the health centres to be good as reflected in the following comments:

"...generally the clinic works well, but the problem is they always start treatment late" (FGD-2, Magoye), "...they are good people... they work well and they teach us a lot of things about the illnesses of our children" (FGD-1 Chivuna).

3.2. Nonavailability of Medicines. Lack of medicines at the health centres is the second barrier that emerged from FGDs as well as interviews with community health workers and health personnel at the RHCs. Both the health care providers and the users (caretakers) were in agreement that medicines were not adequately available. Two main factors were cited as major causes-large catchment population (reported by caretakers) and erratic drug supply from the district health office especially in the six months preceding the interviews (reported by health workers). The women in four FGDs thought the catchment populations were too big for the clinics to provide adequate services. One of the women (FGD-2 Magoye) said:

"... there are too many people in our area and as a result the medicines are always not enough."

The health workers from both health centres reported an erratic supply of drugs that resulted in inconsistent availability of the drugs to patients. Similarly, the community health workers expressed concern on the inadequate quantities of medicines they were given. They received medicines every three months but the medicines only lasted for a month.

3.3. Financial Constraints. Financial constraints posed considerable barriers to accessing needed health care for the children, including issues related to user fees, penalty fees, and high cost of prescription medicines. During FGDs, women noted that they paid K500 (US \$0.17) for registration and K2000 (US \$0.57) for consultation and medication. If they went after working hours they paid K6000 (US \$1.71) as a penalty fee. When health care was sought from the community health worker, they had to pay K1000 (US \$ 0.29) for the service. Caretakers in Chivuna were also allowed to pay in kind to the health centre if they had no money. One caretaker (FGD-2 Chivuna) said:

"... if you have no money we used to leave anything like chitenge (common linen for women) at the clinic then have your child treated, and when you found the money you paid and collected your chitenge."

However, it was reported that this system had since been stopped because the clinic had accumulated too many chitenge materials. The abolishing of this payment system was seen as a significant barrier to accessibility of health care because families without available cash could no longer receive treatment. The women noted:

"...nowadays if you don't have money you just have to take your child back home without treatment" (FGD-1 Chivuna),

"... if your child is admitted at the clinic and you don't have money RHC staff won't give you medicines at the time you are discharged, but only after you have paid..." (FGD-1 Chivuna), 
"... children end up dying at home when medicine is there at the clinic" (FGD-2 Chivuna).

When asked if they thought the user fees were useful for the running of the clinic, most FGDs agreed that they were useful, but two concerns were raised on the user fees. Firstly, families paid user fees but when they went for treatment they were not given any medicines and were told to buy the medicines from retail pharmacies. As a result, some caretakers had the notion that their money was being misappropriated, as expressed by the caretakers:

"... we pay them money but they don't give us medicines... where does our money go" (FGD-1 Magoye),

"They get K2000 (US \$ 0.57) from patients even when they know they don't have medicines" (FGD2 Magoye).

Second, it was known to participants that under-five children were not supposed to pay for health care and they wondered why they were still being asked to pay. One woman (FGD-1 Magoye) asked:

"Why do we pay for under-five children when on the radio they say a European country has given money to our government so that health care is free for under-fives and the elderly above 65 years old?"

However, the health workers explained that for Magoye RHC the under-five children and the elderly over 65 years only paid penalty fees and not any other charge. In addition the two RHCs, though in rural areas, were regarded as municipal health centres, that is, semiurban, because Mazabuka district was not a rural district but a municipal one. Therefore, the free-treatment policy did not apply to the two RHCs, in the strict sense.

3.3.1. Inadequate Staffing. The issue of poor staffing at the health centre was raised in most FGDs, and it was thought to be a contributing factor to the poor performance of the health centres. Each of the health centres was supposed to have two clinical officers and ten nurses, but only had one clinical officer and six and seven nurses in Magoye and Chivuna, respectively. It was expressed in one FGD that the health workers worked hard but the problem was they were too few. However, the Magoye caretakers strongly believed that even if the health workers were few they would have been performing better if the relationship with each other was good, which was not the case. For instance one caretaker (FGD-1 Magoye) noted:

$$
\begin{aligned}
& \text { "... it's like each one of them works for a differ- } \\
& \text { ent organization ... they need to resolve whatever } \\
& \text { problems exist between them." }
\end{aligned}
$$

Some health workers from Magoye also acknowledged the existence of the poor relationship among them. However, in Chivuna the staff generally thought there was a good working relationship among them. No FGD in Chivuna talked of bad relations among health workers.
3.3.2. Lack of Outreach Programmes during Certain Months. Three FGDs raised the issue of health centres not conducting outreach under-five programmes during certain months. Normally, the health centres conduct under-five outreach programmes at community level once every month. However, it was learnt that this was not always the case. Sometimes four months would elapse without any outreach programme, especially in Magoye. This was perceived as having resulted in a reduction in the number of caretakers who took their children to the health centre during CHW partly because of reduced interaction between health centre staff and communities, thereby limiting the information flow from the health centres to the communities. One caretaker said:

"They are not serious... they don't come for outreach but want us to go to them... they have neglected us" (FGD-2, Magoye).

The health workers at the clinics agreed with the nonprovision of outreach programmes at times and attributed it to lack of transport, as expressed in the following quotes:

"The one vehicle we have is not in a very good condition and is broken down most of the times," (health worker from Magoye),

"...today we went for outreach and don't find anyone because we did not have transport to go and confirm with the community on the date for outreach" (health worker from Magoye),

"... Sometimes the vehicle is being used for other activities and there is no transport to go for outreach" (health worker from Chivuna).

3.4. Perceived Barriers to Use of Child Health Weeks. The FGDs specifically touched on the factors responsible for the low attendance observed during CHWs (polio days as they are commonly called). The issues that came out of the FGDs could be categorized as health services related issues, spatial factors, attitude of caretakers, and other family related issues.

3.4.1. Health Services Issues. Four main concerns were raised that relate to health services. First, caretakers complained of the bad timing of CHWs in relation to the season and people's daily activities. They said during the June $\mathrm{CHW}$ it was too cold at times and some caretakers preferred to stay home instead of standing in the cold with the children at the health centre. They said:

"It is too cold for children... sometimes you have to wait a long time for them (health workers) to come..." (FGD-1 Chivuna),

"... why is it held in the cold season? It's cold to walk all the way from home and to come and queue up at the health centre for a long time." (FGD-2 Chivuna).

The December CHW was also perceived as not well timed because of two reasons: it coincided with the planting season 
for maize (staple food) when all women were busy in their fields. In addition, when it rained it was difficult to walk through the rains or on the muddy roads, as expressed in the following quotes:

"...we, the caretakers, are too busy that time... we spend all our time in the fields..." (FGD-2 Magoye),

"... sometimes it's impossible to leave the fields even for a day because child health week may coincide with the days when the people helping you to cultivate your field are available" (FGD-2 Chivuna),

"... if it rains very few caretakers will walk in the rains to take children for child health week, especially if the children are older and are fully vaccinated..." (FGD-2 Chivuna),

"... caretakers want to go for child health week, but it's inconvenient to walk in the mud and difficult to cross our stream if it's just been raining" (FGD-1 Magoye).

The concerns about the rainy season were also expressed by health workers from both health centres saying the health centres were inaccessible to a number of families because streams got filled up, and some roads were hardly passable.

Second, the caretakers said they sometimes did not receive information concerning the days for $\mathrm{CHW}$. The women noted:

"... In our area we hardly get the child health week notices, except from friends..." (FGD-1 Magoye),

“... caretakers who do not attend monthly underfive clinics (cipimo) miss the child health week because that's when the dates are communicated to us" (FGD-2 Chivuna).

However, it was also revealed that they sometimes received the information but late, as expressed in the following comments:

"Our community health worker tells us but usually late, maybe a day before or early in the morning on the actual day. By that time one might have already made other plans for the day..." (FGD2 Chivuna),

"... they tell our school children to inform us, but the children sometimes forget and only tell us after the child health week outreach day is past in our community" (FGD-1 Chivuna).

The health workers were to some extent in agreement with the caretakers when asked to comment on the communication problems. They said communication was sometimes not effective for two main reasons. Information about the dates of CHW was sometimes communicated to caretakers during monthly under-five clinics. As a result, caretakers who did not attend monthly under-five clinics regularly did not receive the notification promptly. They also mentioned that community activities like traditional ceremonies, meetings, and seasonal work were a major deterrent to attending the monthly underfive clinics and $\mathrm{CHW}$, as expressed in the following quote:

"... if there is a funeral or a church meeting in the community all caretakers will attend that congregation and will not come for under five clinic or child health week... it is worse when there is distribution of free food (Civolevole) by some charitable organization" (health worker from Chivuna).

Inaccessibility of some areas, especially during the rainy seasons, was another factor making it difficult for health staff to deliver reminders for $\mathrm{CHW}$ to central places like the headmen, churches, and schools. This resulted in information reaching the caretakers late or not at all.

It was also noticed from the FGDs that the attitude of some health workers towards clients was not good and was a discouragement to some caretakers. They said that some workers were not kind while others were not respectful, as expressed in the following comments:

"...we always want to go for child health week but the health workers discourage us. . . they don't treat us with respect..." (FGD-2 Magoye),

"Some of the health workers have a bad attitude towards caretakers, always scolding at us, especially if you look poor and don't have nice clothes" (FGD-1 Magoye).

In addition, because of the negative attitude of some health workers towards caretakers who had lost under-five cards, caretakers were reluctant to go to the health centre for $\mathrm{CHWs}$ for fear of scolding by the health workers.

The health centres were blamed for changing medicines, time and again, and as a result it made the children sick. This was in situations when the health centres used albendazole instead of the mebendazole that was commonly used for deworming during $\mathrm{CHW}$. The caretakers perceived albendazole to be too strong for the children. They noted:

"... why do they use the other drug (albendazole)... it makes the children sick..." (FGD-2 Chivuna),

"...some caretakers do not like the change of drug... they think the new drug is for adults and makes the children sick" (FGD-2 Chivuna).

3.4.2. Spatial Factors. Long distance to the health centres was one of the factors that emerged from the discussions as being a major difficulty to attending CHWs among the women. They said the distance was too long for some caretakers and it was difficult or impossible to carry all children with them. It was particularly tiresome with bigger children that were heavy to carry and at the same time could not walk on their own all the way. For example they said: 
"... some of our homes are very far from either the health centre or outreach post and it's difficult to walk all the way with a child on the back, especially if you've been working..." (FGD2 Chivuna),

"... it's difficult to carry all children with you if you stay very far from the health centre, especially older ones... you can't make them walk, it's too far, and you can't carry them especially if you have a younger child as well" (FGD-1 Magoye).

3.4.3. Caretakers' Attitude. The third category of barriers to $\mathrm{CHW}$ that emerged from the FGDs relates to the attitude of caretakers, and three main factors were identified. First, caretakers were of the view that some parents were just lazy in taking their children for CHWs as expressed in the following remarks:

"... some of us parents are just lazy to walk or carry children for child health week...” (FGD-1 Chivuna),

"... once in a while we all feel lazy to walk to the health centre and just decide to stay home." (FGD2 Magoye).

They said laziness was coupled with ignorance on the importance of vitamin A, deworming, and growth monitoring of the children. Expressions like the following were common in the FGDs:

"... the health workers must just keep on educating us because what makes us lazy to go for child health week is ignorance... we don't know the importance of taking our children for treatment" (FGD-1 Chivuna).

Second, it was a common practice to stop taking children for $\mathrm{CHW}$ who are aged 2 years and above. This was in part due to the fact that at 2 years the child would have been fully vaccinated and only went to the health centre to receive anthelminthic drugs, vitamin A supplementation, and for growth monitoring. This and the fact that older children were heavier to carry compared to younger ones were important factors. One woman said:

"... it is a common practice for caretakers to stop taking children who are 2 years and above... maybe they think vitamin $A$ and deworming are not important." (FGD-1 Magoye).

Similarly, children who are no longer breast-feeding are also not consistently taken for $\mathrm{CHW}$ in a number of cases. It is believed that a child who has been weaned will have developed a strong body to fight diseases and therefore do not need to rely on medication so much. Third, some caretakers were reported to travel too much such that each time there was CHW either the caretaker or both the caretaker and the child were away. This was particularly raised in the Chivuna FGDs, where for example one woman (FGD-2 Chivuna) said: "...some women are like men; always travelling... that's why they are never around during child health week..."

3.4.4. Other Issues. Other important issues came up in the discussions that were believed to affect attendance during CHWs. The lack of family planning in certain families resulted in a woman having 2 to 3 under-five children at one time and therefore making it difficult for her to go with all of them to the health facility. This further led to the caretaker only taking the youngest one or two and leaving behind the older one(s). The caretakers remarked:

"...families need to learn to widely space their children... it is not easy to carry two or three under-five children to the health centre, and stay with them for a long time... they start crying" (FGD-1 Magoye).

The second issue was illness of either the caretaker or the child that made some caretakers to miss the $\mathrm{CHW}$, as noted from the following remarks:

"... other things can't be controlled, for example if a woman is sick then the child will not be taken to the health centre... we need men to get involved" (FGD-2 Chivuna).

This issue brought up the suggestion of men involvement in health care matters for their children as being part of the solution to some of the problems.

3.5. Coping with Barriers to Health Care and Caretakers Suggested Solutions for Child Health Week. Participants were asked how they tried to cope with the problem of inaccessibility to health care services for their children. The main coping strategy was the use of alternative health care providers, for example, traditional healers. From the caretakers' discourse five main patterns of use of traditional healers emerged. First, traditional healers were used as the first resort for all illnesses by many caretakers. When they did not get the desired results that is when they took the children to the clinic. Second, the families resorted to traditional healers when there was no medicine at the clinic and could not afford to buy the medicine from the pharmacy. Third, the traditional healers were used by the caretakers because they were perceived as affordable compared to the clinic. One caretaker said:

"...we always use traditional healers unless we find money to take the child to the clinic" (FGD-2 Magoye).

Fourth, the traditional healers were consulted for persistent illness that the clinic had "failed" to cure. Fifth, they used the traditional healers for specific illnesses, for example, mouth ulcers, convulsions, epilepsy, rash, swollen feet, and when a breast feeding caretaker becomes pregnant and the child becomes sick.

In addition to the traditional healers, traditional medicines were also shared among the lay people who usually were 
already linked to one another by ties of kinship, friendship, neighbourhood, or religious organizations. In the kinship the older members of the families, that is, grandparents, uncles, aunts, and parents, were an important source of traditional remedies. Apart from relatives, there were individuals in the neighbourhood to whom other people went to seek advice on health matters. These could be people who have a lot of experience in dealing with particular illness either because their children had experienced the illness in question, or because they lived in a community in which the specific illness was highly prevalent. The sharing of knowledge concerning herbal remedies for various illnesses was said to be common among women's organizations in various churches.

Caretakers were further asked to suggest what they thought could be done to ensure that more children attend CHWs. The main suggestions were to increase the number of treatment days for $\mathrm{CHW}$ at the outreach points from one to between two and five, to increase the number of treatment sites, to change the timing of CHW from June and December to for instance April and October, to inform all community members in good time, to encourage fathers to help caretakers in carrying the children to the health centres, to start using community health workers to treat children at home, to give under-five cards to all children who do not have, and to start conducting health education meetings in the communities on the importance of CHW.

\section{Discussion}

The present study identified both provider and consumer barriers to health care access for under-five children as described in previous studies [1, 2, 11]. Ensor and Cooper [12] defined provider determinants of health care access as "those factors derived from health care production that interact to produce health care services." These include availability of medicines, qualified staff and their attitude, appropriate technologies, materials, capital equipment, health priorities, and health system issues. Consumer determinants of access to health care were defined as "those factors that influence demand and that operate at the individual, household, or community level" [12]. Individual and household factors include age, sex, income, education, and knowledge about illnesses and need for medical treatment. Community factors include cultural and religious influences and other social factors that affect individual preferences.

A number of studies have reported that caretakers' perception of the attitude of the health workers formed a barrier for accessing the demanded health services [13-15]. Mobilizing demand for child survival interventions may be ineffective if the actual or perceived quality of general health care services is low. For caretakers in our study, the concept of quality of care included elements of health worker attitude, communication, the kind of attention they received, equity of receiving health care, and availability of medicines. One of the underlying factors to the bad health worker attitudes and poor attention given is inadequate numbers of skilled health workers, identified by two FGDs and also reported by other studies [4]. Efforts to improve the responsiveness and quality of health services and of health care providers will make health care to be more accessible to the users and will be of benefit to communities. The responsiveness of health services may be enhanced by improving staff attitudes and communication skills [16].

The scheduling of the CHWs may also be considered as an important factor that has significant impact on responsiveness of health care services. The rainy season (November to March) is the peak-planting season for farmers. The high opportunity cost of time in taking children for $\mathrm{CHW}$ instead of going to the fields is likely to make CHW less accessible in the rainy season. Earlier studies found that a significantly lower proportion of people were likely to utilize the health services in the wet season compared to the dry season $[17,18]$. The high opportunity cost of time is compounded by the muddy roads and flooding streams that make travel to the health facilities very difficult in the rainy season. On the other hand, the current study found that the long waiting time at the health facilities is an important deterrent to some caretakers in attending CHW especially during the cold season. In general health care, long waiting time at the health facility between registration and consultation, and between consultation and getting the drugs, has been identified as one of the major areas of dissatisfaction with the health services, as well as the cause of none utilization of the health services $[17,19]$. These findings can be extended to explain the reasons given by caretakers in our study of how the cold season is not favourable to some of them, especially when they had to wait for a long time at the health facilities before the children were treated. A reduction in the opportunity cost of time in the rain and cold seasons and the inconvenience of long waiting time in the cold season could enhance the utilization of health services. This could be achieved by either strengthening and expanding outreach services or rescheduling of CHWs to other times of the year.

The current study as well as earlier studies $[5,13]$ recognizes the lack of communication and information transfer between the health providers and the caretakers as an important deterrent to accessing the services. Caretakers in our study complained of, for instance, not being informed of what illness their children were suffering from and also what medicines were administered to the children. Lapses in communication were also noted in relation to $\mathrm{CHWs}$, where the time between notification of community members and the $\mathrm{CHW}$ was reported as inadequate. Focused efforts are therefore required to ensure that communication strategies and messages used enable increased information flow and the resultant accessibility to services.

The cost of seeking health care for sick children is a major obstacle in many settings $[2,6]$. Strategies to reduce the cost of health care may improve the accessibility of health care services for poor households. The abolishment of user fees has been shown to lead to increased utilization of health services $[5,20]$. After fifteen years of implementing user fees in Zambia, great concerns were raised about the role of user fees in populations with widespread poverty. The government abolished user fees for primary care in all rural areas, effective from April 1, 2006 [20]. Fifty-six of the then 72 districts in Zambia were classified as rural, but there still is a problem with this official classification because several 
districts contain both urban and rural sections. Chivuna and Magoye, for instance, are rural areas of Mazabuka district, but Mazabuka district is not a rural district. This classification problem was evident from the responses of health workers concerning user fees. Revision of the classification might be needed; this time focussing on the health centre rather than the district. There is also the barrier caused by unofficial fees, as noted by the FGDs. Unofficial fees have been defined as payments to individuals or institutions in cash or in kind made outside official payment channels for services that are meant to be free of charge [21]. In the current study unofficial fees in the form of penalty fees were reported as a barrier to health care. Despite being identified as a barrier to health care on one hand, unofficial fees have on the other hand been identified as playing positive roles to the health system in some settings. Unofficial fees have been associated with staff motivation and better performance of the staff in terms of hours worked and utilization rates of services [22, 23]. The effect of these fees in motivating health workers is supported by a study in Cambodia where formalization of unofficial fees and improvement of health worker remuneration, proportional to amounts they were receiving from unofficial payments, led to increased levels of utilizing health services [24]. In addition, the unofficial fees collected by the health centres have been used as petty cash for buying supplies like washing detergents and stationary (RHC workers, personal communication). However, the unofficial fees also have been shown to have negative effects on the health workers in terms of job satisfaction and motivation to work. Participants in a study in Tanzania mentioned that they felt enslaved by patients as a result of being bribed and that this lead to loss of self esteem. Fear of detection was a main demotivating factor [25]. These factors seem to counterbalance the positive effect of financial incentives. The issues of unofficial fees need to be considered in local context in order to mitigate its effect on the accessibility of health services.

Long distance to health facilities has been identified in many studies as an important barrier to health care in rural areas $[5,11]$. Children who live closer to the health facility are more likely to utilize the health services than are children who live farther away. Approaches that can alleviate the distance problems include strengthening of the existing outreach programmes and strengthening and extending services of community health workers to ensure targeted delivery of services closer to the households [26]. The outreach programmes can be strengthened by ensuring that transport is always available for these programmes [27] and by increasing the number of outreach posts where necessary and feasible, as suggested by the participants in the current study. Caretakers in the current study also suggested that men involvement in matters concerning the health of their children, for example, taking children for $\mathrm{CHW}$, can help increase the number of children attending. Men involvement in health matters has been shown to increase the utilization of health care services and in turn improve child health in communities [28]. This is because men play important roles in regulating women's access to health services through the control of finances, women's mobility, and health care decisions [29]. Therefore, efforts should also focus on involving fathers in child health issues, at the same time empowering caretakers with the ability to manage issues of child health care.

Interventions also need to address the demand-side barriers to health care in addition to the supply-side barriers. This includes the need to increase the awareness and understanding of child illnesses and the available preventive and curative services among community members. Issues of laziness, ignorance, and not taking children older than 2 years can be targeted by such efforts. Communication channels to disseminate health-related information, education, and communication (IEC) need to be strengthened to reach target community members. Various communication channels like dances, public lectures, and role plays have been shown to be effective in rural settings $[30,31]$. In recent years, traditional healers in Zambia have been trained and used as channels to disseminate basic information on HIV/AIDS, malaria, child health, and tuberculosis (Zambia integrated health program, unpublished data). This avenue is still being developed and can also be explored further as part of the strategy to reach as many community members as possible with health messages.

The provision of health care as well as the services to deliver them and ensuring that the health care is of good quality are major challenges in resource-poor settings [2]. Additional efforts are therefore needed to ensure that these interventions reach the poor and achieve coverage levels that can lead to significant reduction in child mortality. Given the findings from our study, interventions to enable people to gain access to health care in rural areas like Magoye and Chivuna have to focus on improving the responsiveness of health care services, information flow between health care providers and users, strengthening of existing outreach programmes, raising awareness levels on child health issues to increase demand for health services, exploration of appropriate incorporation of other health sectors into the formal sector, and promoting men involvement in child health issues at household level.

\section{Acknowledgments}

The authors thank the Mazabuka district health office, Chivuna RHC, Magoye RHC, and the community leaders for allowing the study to be conducted in the study area. Gratitude is extended to the caretakers and health workers who participated in the study. The authors also thank DBLCentre for Health Research and Development, Faculty of Life Sciences, University of Copenhagen, Denmark, for the financial support. All authors planned and designed the study protocol; H. Halwindi conducted the data collection and managed the fieldwork and analysed and interpreted the study assisted by A. Olsen, P. Magnussen, and S. Siziya. H. Halwindi drafted the paper and all authors read and approved the final paper. H. Halwindi is the guarantor of the paper. The authors have no conflict of interests concerning the reported work in this paper.

\section{References}

[1] D. Gillespie and L. Packard, "Knowledge into action for child survival," Lancet, vol. 362, no. 9380, pp. 323-327, 2003. 
[2] B. Obrist, N. Iteba, C. Lengeler et al., "Access to health care in contexts of livelihood insecurity: a framework for analysis and action," PLoS Medicine, vol. 4, no. 10, article e308, 2007.

[3] C. Mukuka, M. Siame, P. Kalwesha, and K. Mwinga, Zambia Child Health Situation Analysis, MoH/CBoH/WHO/UNICEF, 2004.

[4] World Health Organization, Reaching the Poor: Challenges for Child Health in the Western Pacific Region, World Health Organization, Manila, Philippines, 2007.

[5] S. N. Kiwanuka, E. K. Ekirapa, S. Peterson et al., "Access to and utilisation of health services for the poor in Uganda: a systematic review of available evidence," Transactions of the Royal Society of Tropical Medicine and Hygiene, vol. 102, no. 11, pp. 1067-1074, 2008.

[6] C. Malama, Q. Chen, R. De Vogli, and G. L. Birbeck, "User fees impact access to healthcare for female children in rural Zambia," Journal of Tropical Pediatrics, vol. 48, no. 6, pp. 371372, 2002.

[7] G. Jones, R. W. Steketee, R. E. Black, Z. A. Bhutta, and S. S. Morris, "How many child deaths can we prevent this year?" Lancet, vol. 362, no. 9377, pp. 65-71, 2003.

[8] Ministry of Health of Zambia, National Health Strategic Plan 2006-2010: Towards Attainment of the Millennium Goals and National Health Priorities, Ministry of Health, Zambia, 2005.

[9] Central Statistical Office [Zambia], Central Board of Health [Zambia], and ORC Macro, Zambia Demographic and Health Survey 2001-2002, Central Statistical Office, Central Board of Health, and ORC, Calverton, Md, USA, 2003.

[10] P. R. Ulin, T. R. Elizabeth, and E. E. Tolley, Qualitative Methods in Public Health: A Field Guidefor Applied Research, JosseyBrass, San Francisco, Calif, USA, 2005.

[11] C. Baume, D. Helitzer, and S. P. Kachur, "Patterns of care for childhood malaria in Zambia," Social Science and Medicine, vol. 51, no. 10, pp. 1491-1503, 2000.

[12] T. Ensor and S. Cooper, "Overcoming barriers to health service access: influencing the demand side," Health Policy and Planning, vol. 19, no. 2, pp. 69-79, 2004.

[13] A. Topuzoğlu, P. Ay, S. Hidiroglu, and Y. Gurbuz, "The barriers against childhood immunizations: a qualitative research among socio-economically disadvantaged mothers," European Journal of Public Health, vol. 17, no. 4, pp. 348-352, 2007.

[14] P. Streefland, A. M. R. Chowdhury, and P. Ramos-Jimenez, "Patterns of vaccination acceptance," Social Science and Medicine, vol. 49, no. 12, pp. 1705-1716, 1999.

[15] P. H. Streefland, "Public doubts about vaccination safety and resistance against vaccination," Health Policy, vol. 55, no. 3, pp. 159-172, 2001.

[16] J. A. Schellenberg, J. Bryce, D. De Savigny et al., "The effect of Integrated Management of Childhood Illness on observed quality of care of under-fives in rural Tanzania," Health Policy and Planning, vol. 19, no. 1, pp. 1-10, 2004.

[17] R. Sauerborn, A. Nougtara, M. Hien, and H. J. Diesfeld, "Seasonal variations of household costs of illness in Burkina Faso," Social Science and Medicine, vol. 43, no. 3, pp. 281-290, 1996.

[18] J. I. Litvack and C. Bodart, "User fees plus quality equals improved access to health care: results of a field experiment in Cameroon," Social Science and Medicine, vol. 37, no. 3, pp. 369383, 1993.

[19] B. K. Patro, R. Kumar, and A. Goswani, "Community perception and client satisfaction about the primary health care services in an urban resettlement colony of New Delhi," Indian Journal of Community Medicine, vol. 33, no. 4, pp. 250-254, 2008.
[20] F. Masiye, B. M. Chitah, P. Chanda, and F. Simeo, Removal of User Fees at Primary Health Care Facilities in Zambia: A Study of the Effects on Utilisation and Quality of Care, EQUINET discussion paper series 57, EQUINET, UCT HEU, Harare, Zimbabwe, 2008.

[21] M. Lewis, Who Is Paying for Health Care in Eastern Europe and Central Asia? World Bank Publication, 2000.

[22] B. McPake, D. Asiimwe, F. Mwesigye et al., "Informal economic activities of public health workers in Uganda: implications for quality and accessibility of care," Social Science and Medicine, vol. 49, no. 7, pp. 849-865, 1999.

[23] J. R. Killingsworth, N. Hossain, Y. Hedrick-Wong, S. D. Thomas, A. Rahman, and T. Begum, "Unofficial fees in Bangladesh: price, equity and institutional issues," Health Policy and Planning, vol. 14, no. 2, pp. 152-163, 1999.

[24] S. Barber, F. Bonnet, and H. Bekedam, "Formalizing under-thetable payments to control out-of-pocket hospital expenditures in Cambodia," Health Policy and Planning, vol. 19, no. 4, pp. 199208, 2004.

[25] S. Stringhini, S. Thomas, P. Bidwell, T. Mtui, and A. Mwisongo, "Understanding informal payments in health care: motivation of health workers in Tanzania," Human Resources for Health, vol. 7, article 53, 2009.

[26] C. G. Victora, A. Wagstaff, J. A. Schellenberg, D. Gwatkin, M. Claeson, and J. P. Habicht, "Applying an equity lens to child health and mortality: more of the same is not enough," Lancet, vol. 362, no. 9379, pp. 233-241, 2003.

[27] W. K. Bosu, D. Ahelegbe, E. Edum-Fotwe, Kobina A Bainson, and P. Kobina Turkson, "Factors influencing attendance to immunization sessions for children in a rural district of Ghana," Acta Tropica, vol. 68, no. 3, pp. 259-267, 1997.

[28] E. Sloand and B. Gebrian, "Fathers clubs to improve child health in rural Haiti," Public Health Nursing, vol. 23, no. 1, pp. 46-51, 2006.

[29] World Health Organization, Programming for Male Involvement in Reproductive Health: Report of the Meeting of WHO Regional Advisers in Reproductive Health WHO/PAHO, UNDP/ UNFPA/WHO/World Bank/TDR, Washington, DC, USA, 2002.

[30] M. W. Hetzel, N. Iteba, A. Makemba et al., "Understanding and improving access to prompt and effective malaria treatment and care in rural Tanzania. The ACCESS Programme," Malaria Journal, vol. 6, article 83, 2007.

[31] L. Ewles and I. Simnett, Promoting Health: A Practical Guide, Bailliere Tindall, Edinburgh, 4th edition, 1999. 


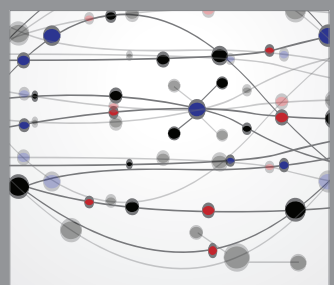

The Scientific World Journal
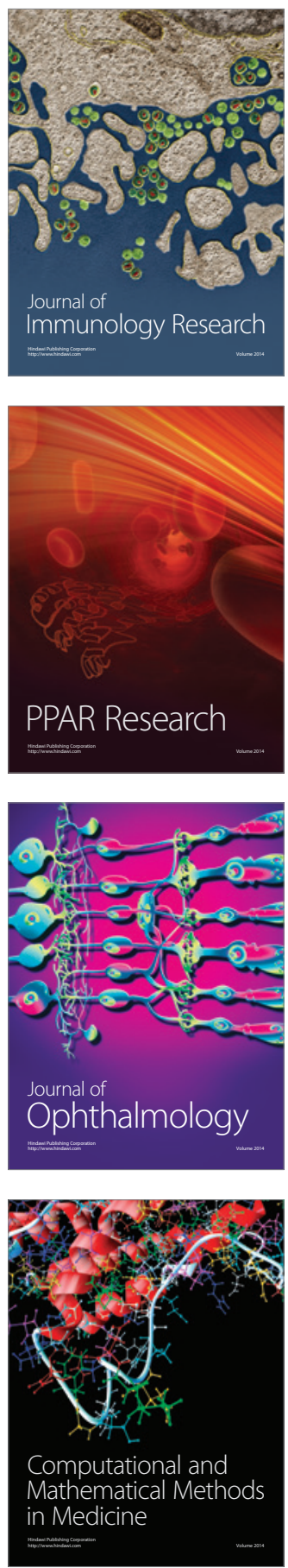

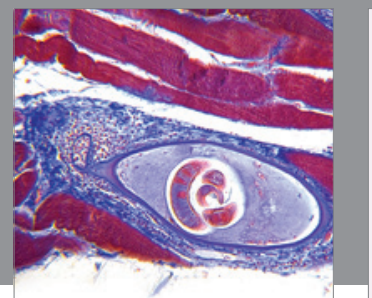

Gastroenterology

Research and Practice
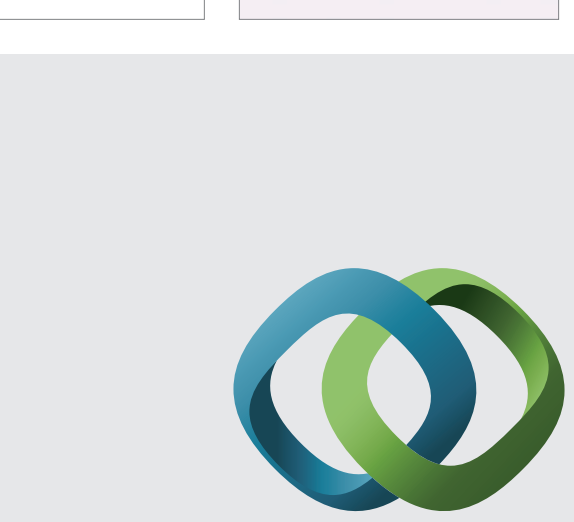

\section{Hindawi}

Submit your manuscripts at

http://www.hindawi.com
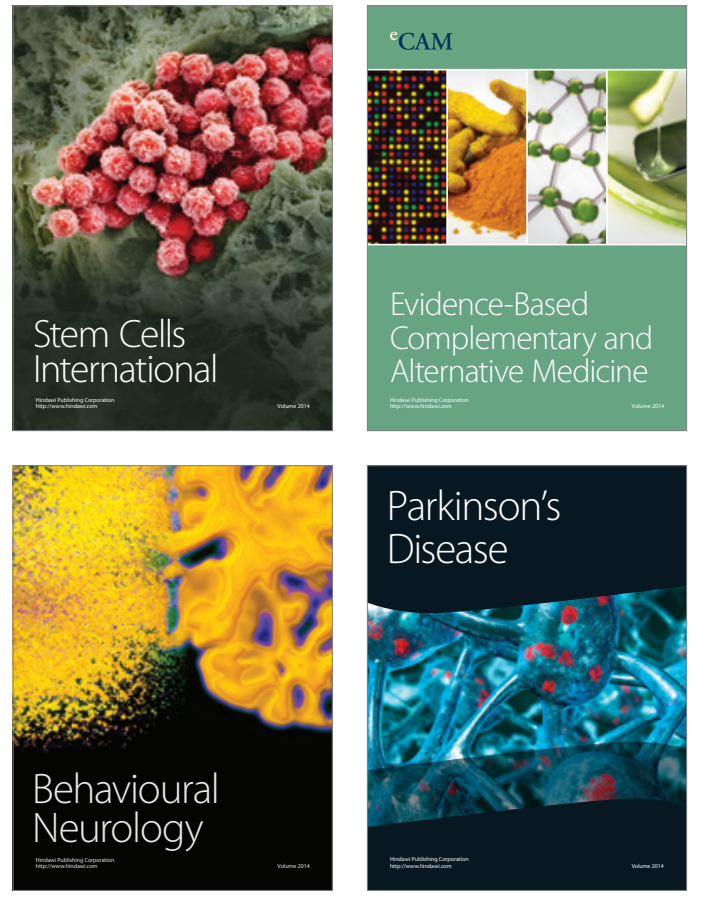
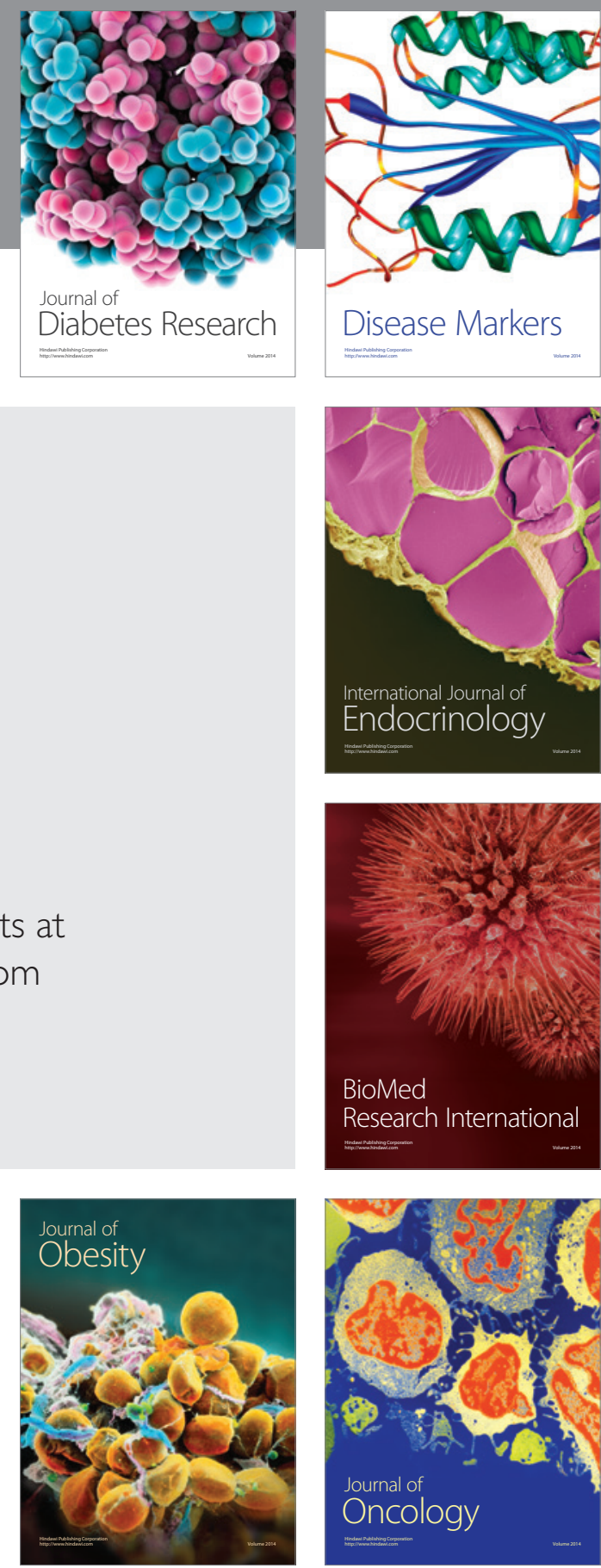

Disease Markers
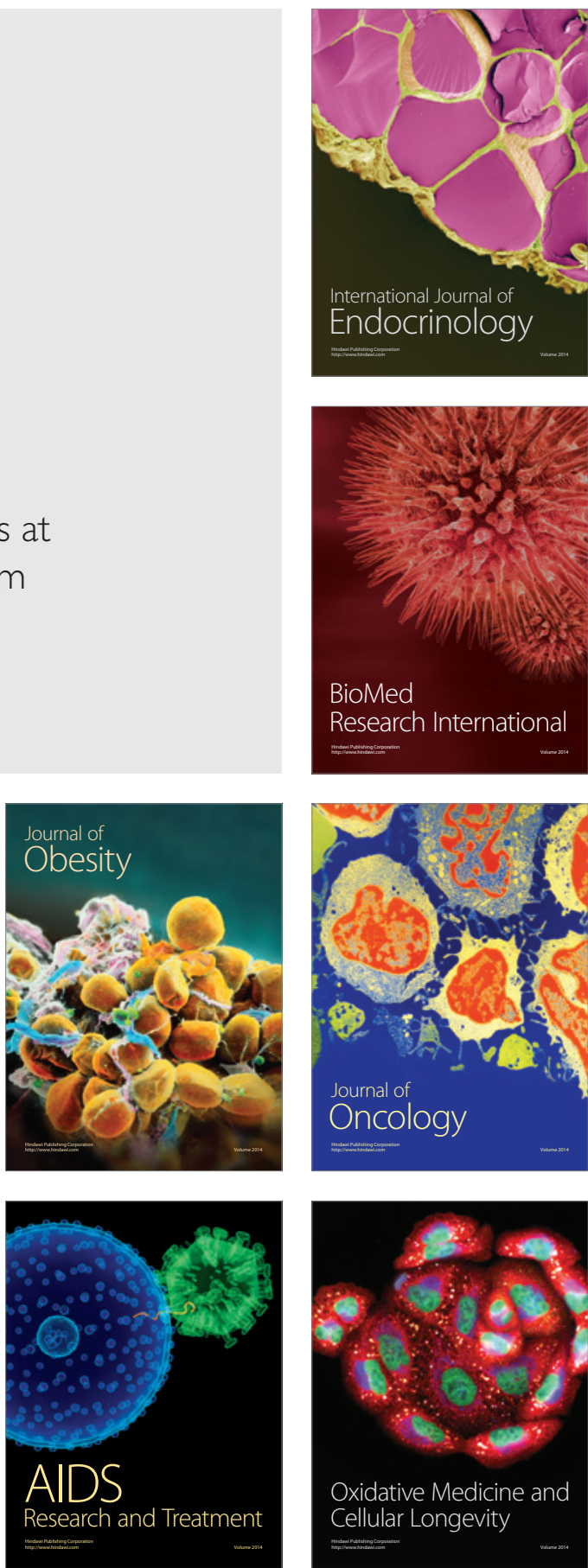